\title{
PEMANFAATAN POS PEMBINAAN TERPADU (POSBINDU) TERHADAP PENGENDALIAN HIPERTENSI PADA WARGA DI TANGERANG
}

\author{
Riama Marlyn Sihombing ${ }^{1}$, Fiolenty Sitorus ${ }^{2}$, Fransiska Ompusunggu ${ }^{3}$, Triulan Sidabutar ${ }^{4}$ \\ Lisandra Maria G. B. Sidabutar ${ }^{5}$ \\ ${ }^{1,2,3,4}$ Fakultas Keperawatan Universitas Pelita Harapan Tangeraang Banten \\ ${ }^{5}$ Institute of Nutrition, Mahidol University, Thailand \\ email riama.sihombing@uph.edu, fiolenty.sitorus@uph.edu, fransiska.ompusunggu@uph.edu, \\ maria.bernadett28@gmail.com
}

\begin{abstract}
Abstrak
Sustainable Development Goals (SDGs) 2030 menjadikan Penyakit Tidak Menular (PTM) sebagai prioritas nasional. PTM - diantaranya hipertensi - sering tidak terdeteksi karena tidak menimbulkan gejala atau keluhan dan biasanya ditemukan pada tahap lanjut sehingga sulit disembuhkan dan dapat menyebabkan kecacatan atau kematian dini. Salah satu cara mengendalikan PTM melalui kegiatan Posbindu PTM.Tujuan kegiatan pengabdian masyarat ini untuk mengetahui pemanfaatan Posbindu PTM terhadap pengendalian hipertensi pada warga RW 05 Kelurahan Bencongan Indah Tangerang Banten. Metode menggunakan kuantitatif korelasional dengan pendekatan cross sectional. Populasi adalah warga yang berusia 29-85 tahun dengan sampel 83 orang. Implementasi meliputi pengukuran tekanan darah dan pemeriksaan kadar kolesterol darah. Dari kegiatan pengabdian masyarakat ini didapatkan warga yang memanfaatkan Posbindu PTM sebanyak 36,1\%, sebagian besar $(74,7 \%)$ berjenis kelamin perempuan, lebih dari setengah $(68,6 \%)$ menunjukkan tekanan darah tidak normal sedangkan hasil pemeriksaan kolesterol darah hampir berimbang antara nilai yang normal dan tidak normal. Data dianalisa menggunakan Chi-square dengan tingkat kesalahan 0,05 didapatkan ada perbedaan tekanan darah $(\mathrm{p}=0,005)$ dan tidak ada perbedaan hasil kolesterol $(\mathrm{p}=1,00)$ pada pemanfaatan Posbindu PTM. Kegiatan pengabdian masyarakat selanjutnya perlu menganalisa faktor-faktor yang berhubungan dengan pemanfaatan Posbindu PTM dan meningkatkan pemahaman warga tentang pentingnya kegiatan Posbindu PTM.
\end{abstract}

Kata Kunci: pemanfaatan, posbindu, hipertensi, penyakit tidak menular

\section{PENDAHULUAN}

Penyakit tidak menular (PTM) dijadikan prioritas nasional dalam Sustainable Development Goals (SDGs) 2030. PTM adalah penyakit kronis degenaratif yang bukan disebabkan oleh infeksi kuman diantaranya penyakit jantung, diabetes mellitus (DM), kanker, penyakit obstruktif kronis (PPOK) dan gangguan akibat kecelakaan dan tindak kekerasan. (Pusat Data dan Informasi Kemenkes RI, 2012). Penyakit ini sering tidak terdeteksi karena tidak menimbulkan gejala atau keluhan dan biasanya ditemukan pada tahap lanjut sehingga sulit disembuhkan dan dapat menyebabkan kecacatan atau kematian dini.

Hipertensi merupakan salah satu PTM yang menjadi masalah kesehatan yang serius. Menurut kriteria Join National Committee (JNC VII, 2007) menyatakan bahwa hipertensi adalah suatu penyakit yang ditandai dengan peningkatan tekanan darah di atas normal dengan nilai sistolik $>140 \mathrm{mmHg}$ dan sistolik > 90 mmHg. Berdasarkan Badan Kesehatan 
WHO (2018) terdapat sekitar 1,13 miliar orang di dunia menderita hipertensi. Artinya 1 dari 3 orang di dunia terdiagnosis menderita hipertensi. Diperkirakan juga setiap tahun ada 9,4 juta orang meninggal akibat hipertensi dan komplikasi. Jumlah penderita hipertensi di dunia terus meningkat setiap tahunnya, diperkirakan pada 2025 akan ada 1,5 miliar orang yang terkena hipertensi. Diperkirakan juga setiap tahun ada 9,4 juta orang meninggal akibat hipertensi dan komplikasi (Kementerian Kesehatan RI, 2018).

Data Riskesdas 2018 diperoleh prevalensi hipertensi di Indonesia sebesar $34,11 \%$ sedangkan di Provinsi Banten sebesar 29,47\% dan menunjukkan peningkatan prevalensi hipertensi pada penduduk usia 18 tahun ke atas sebesar 9,5\% dibandingkan tahun 2013 (Kementerian Kesehatan RI, 2019). Hal ini sejalan dengan hasil pemeriksaan yang dilakukan di RW 05 Kelurahan Bencongan Indah Tangerang Banten diperoleh warga yang berusia 45-59 tahun menderita hipertensi sebanyak $29 \%$, sebagian besar $(80,6 \%)$ menunjukkan indeks massa tubuh (IMT) obesitas dan lebih dari setengah $(61,2 \%)$ menunjukkan kadar kolesterol meningkat $\geq$ $200 \mathrm{mg} /$ (Sihombing, Sitorus, Ompusunggu, Sidabutar, \& Bernadette, 2018).

Salah satu upaya kesehatan berbasis masyarakat dalam pelaksanaan pengendalian PTM terutama hipertensi dibentuk dan dikembangkan Pos Pembinaan Terpadu (Posbindu) Melalui kegiatan Posbindu PTM dilaksanakan monitoring dan deteksi dini faktor resiko PTM (merokok, pola makan tidak sehat, kurang aktivitas fisik, obesitas, stress, hipertensi, hiperglikemia dan hiperkolesterol) secara terpadu, rutin dan periodic serta menindak lanjutinya secara dini faktor resiko yang ditemukan melalui konseling kesehatan dan segera merujuknya ke fasilitas pelayanan kesehatan dasar. (Pusat Data dan Informasi Kemenkes RI, 2012).

Penyelenggara program Posbindu PTM di kelurahan Bencongan Indah telah tersebar di seluruh RW. Salah satu RW yang menyelenggarakan Posbindu PTM adalah RW 05 kompleks perumahan Harapan Kita yang dikenal dengan nama Posbindu Soka Indah. Posbindu ini merupakan wilayah binaan dari Puskesmas Kelurahan Jalan Kutai yang sudah memiliki kerjasama dengan Fakultas Keperawatan Universitas Pelita Harapan. Posbindu Soka Indah dibentuk pada tanggal 11 November 2014 tapi baru memulai kegiatan pada bulan Februari 2015 dan selanjutnya rutin melakukan kegiatan pada hari Selasa minggu kedua setiap bulan. Pengetahuan kader Posbindu PTM sudah memadai karena ketua kader seorang perawat dan kader mendapat pembinaan dari puskesmas. Namun warga RW 05 belum memanfaatkan posbindu dilihat dari kehadiran hanya 30-40 orang setiap bulan

Berdasarkan pemaparan di atas maka kegiatan pengabdian kepada masyarakat ini bertujuan untuk mengetahui pemanfaatan posbindu PIM terhadap pengendalian hipertensi pada warga RW 05 Kelurahan Bencongan Indah Tangerang Banten.

\section{METODE}

$\begin{array}{crc}\text { Kegiatan } & \text { kepada } & \text { masyarakat ini } \\ \text { menggunakan } & \text { kuantitatif } & \text { korelasi dengan }\end{array}$ pendekatan cross sectional. Lokasi kegiatan di Posbindu Soka Indah Tangerang Banten. Dalam kegiatan ini warga diobservasi sebanyak dua kali kunjungan ke Posbindu yaitu kegiatan edukasi dan pada tanggal 12 April 2018 dan skrining kesehatan pada tanggal 8 Mei 2018. Pemanfaatan posbindu dikatakan aktif jika warga ikut terlibat dalam kedua kegiatan tersebut.

Kegiatan pengabdian kepada masyarakat diawali dengan pertemuan antara ketua kader posbindu Soka Indah dengan dengan tim PkM dari UPH Kegiatan Pengabdian kepada Masyarakat diawali dengan pertemuan antara ketua dengan tim PkM dengan anggota tim untuk menyepakati topik dan kebutuhan materi yang diperlukan saat pelaksanaan PkM. Setelah semua pihak menyetujui kegiatan tersebut, tim meminta persetujuan kepada Kepala UPT Puskesmas Kutai dan Ketua RW 05 serta menyebarkan undangan kepada warga RW 05 Kelurahan Bencongan Indah dengan memberikan informasi akan dilakukan edukasi pencegahan dan pengendalian hipertensi. Selanjutnya tim PkM menyiapkan materi edukasi, kuesioner dan melakukan pembelian barang-barang yang diperlukan seperti poster, goody bag, snack dan peralatan lainnya yang berkaitan dengan kegiatan.

1. Edukasi pencegahan dan pengendalian hipertensi

Kegiatan $\mathrm{PkM}$ ini bertempat di posbindu pada 12 April 2018 pukul 09.00-12.00 wib. Penyuluhan dibuka dalam doa dilanjutkan dengan perkenalan tim kepada peserta dan 
pemberian kata sambutan. Setiap peserta mengisi daftar hadir dan diberikan snack dan goody bag. Selanjutnya pemateri memberikan edukasi kepada peserta dimulai dari pendidikan kesehatan tentang hipetensi dan diet pada hipertensi. Kemudian dilanjutkan dengan sesi tanya jawab atau diskusi. Peserta diberikan kesempatan untuk bertanya tentang materi yang belum dipahami. Pada akhir kegiatan peserta diminta menyampaikan kesan dan pesan tentang edukasi yang telah diberikan dan kegiatan ditutup kembali dengan doa. Peserta juga diinformasikan untuk mengikuti kembali kegiatan yang akan dilakukan pada bulan berikutnya.

2. Skrining kesehatan

Kegiatan PkM dilaksanakan pada tanggal 8 Mei 2018 pukul 09.00-12.00 wib. Pemeriksaan dibagi dalam 4 meja. Pada meja 1 dilakukan registrasi peserta, wawancara singkat tentang latar belakang peserta untuk mengetahui faktor resiko hipertensi. Meja 2 dipersiapkan untuk pemeriksaan tekanan darah, pengukuran tinggi badan dan lingkar perut serta menimbang berat badan. Meja 3 untuk pemeriksaan gula darah sewaktu, kolesterol dan asam urat. Terakhir meja 4 disediakan untuk pemberian informasi kepada peserta terkait dengan hasil yang didapatkan. Hasil dari pemeriksaan diberikan kepada setiap peserta dan diharapkan dapat membangkitkan kesadaran peserta untuk memulai gaya hidup sehat untuk mengendalikan kolesterol dan asam urat.

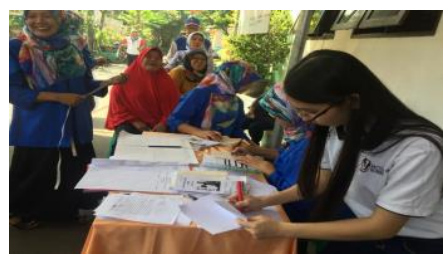

Gambar 3. Meja 1: Pendaftaran peserta

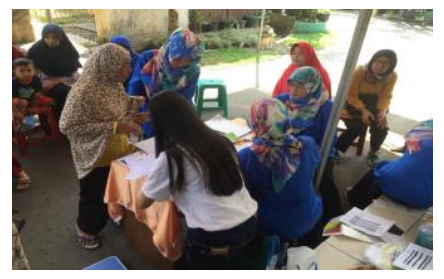

Gambar 4. Meja 2: Pengukuran lingkar perut, tinggi badan dan timbang berat badan

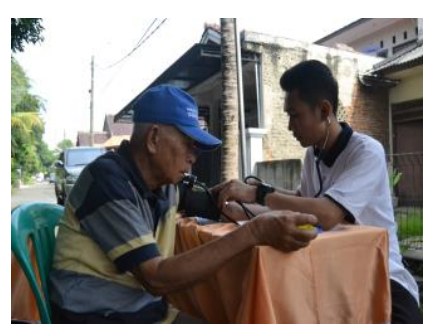

Gambar 5. Meja 2: Pengukuran tekanan darah

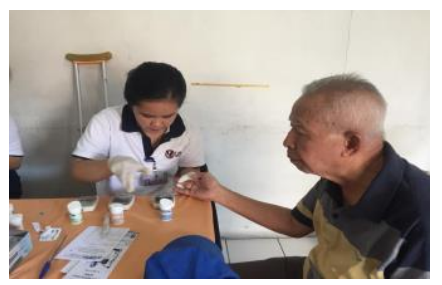

Gambar 6. Meja 3: Pemeriksaan kadar kolesterol total

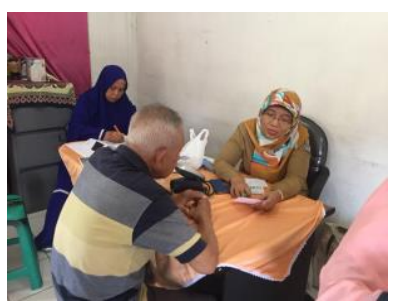

Gambar 7. Meja 4: Konsultasi hasil pemeriksaan dan identifikasi faktor resiko

\section{HASIL DAN PEMBAHASAN}

\section{Pemanfaatan posbindu}

Peserta yang hadir saat kegiatan edukasi dan skrining kesehatan seluruhnya warga yang berasal dari RW 05 Kelurahan Bencongan Indah. Antusiasme warga dalam menghadiri kegiatan ini menunjukkan sebenarnya warga RW 05 peduli dan berkeinginan untuk rutin melakukan pemeriksaan kesehatan, hal ini tampak dari kesediaan warga mengikuti kegiatan edukasi dan skrining kesehatan hingga selesai. Bahkan ada beberapa peserta yang datang lebih awal sebelum kegiatan dimulai.

Seluruh peserta kegiatan berjumlah 83 orang tetapi hanya $30 \quad(36,1 \%)$ warga yang 
mengikuti kegiatan edukasi dan skrining kesehatan. Hal ini berarti lebih dari setengah $(63,9 \%)$ warga tidak aktif memanfaatkan posbindu (tabel 1).

Tabel 1. Distribusi pemanfaatan pelayanan posbindu pada warga $(\mathrm{n}=83)$

\begin{tabular}{ccc}
\hline Pemanfaatan posbindu & Jumlah & $\%$ \\
\hline Tidak aktif & 53 & 63,9 \\
Aktif & 30 & 36,1 \\
\hline
\end{tabular}

Pemanfaatan posbindu pada warga ternasuk kategori rendah. Temuan kemungkinan disebabkan warga belum mempunyai pengetahuan yang memadai tentang penyakitnya sehingga mereka tetap mengkonsumsi makanan yang tidak diperbolehkan, kurang aktivitas fisik dan masih menganggap penyakit hipertensi tidak berbahaya. Selain itu pengetahuan warga yang rendah juga mungkin disebabkan warga kurang memahami siapa sasaran Posbindu dan manfaat adanya Posbindu. Beberapa warga mengatakan bahwa sasaran Posbindu adalah masyarakat kelompok usia lanjut dan manfaat Posbindu hanya untuk memeriksa tekanan darah setiap bulan.

Faktor pekerjaan juga mungkin menjadi penyebab warga tidak aktif. Sebagian besar warga RW 05 adalah pegawai negeri atau pesiunan dari satu rumah sakit pemerintah di Jakarta. Kegiatan Posbindu Soka Indah dilakukan pada pagi hari pkl 09.00 wib sehingga lebih banyak warga yang bekerja pada jam tersebut. Hal ini sesuai dengan penelitian yang dilakukan oleh Sari \& Savitri, (2018) yang mendapatkan warga yang tidak bekerja lebih aktif memanfaatkan Posbindu PTM daripada warga yang bekerja. Warga yang tidak bekerja mempunyai waktu luang lebih banyak daripada waga yang bekerja sehingga memungkinkan mereka lebih aktif memanfaatkan Posbindu. Sedangkan menurut Fuadah \& Rahayu, (2018) pekerjaan berhubungan erat dengan faktor interaksi sosial. Warga yang bekerja lebih memanfaatkan pelayanan kesehatan dikarenakan banyaknya dorongan dari faktor eksternal misalnya teman kerja yang memberikan informasi. Berbeda dengan warga yang tidak bekerja, mereka lebih sedikit mendapatkan informasi tentang suatu pelayanan kesehatan. Namun temuan ini perlu dikaji lebih lanjut. Kegiatan pengabdian masyarakat selanjutnya perlu menganalisa faktor-faktor yang berhubungan dengan pemanfaatan Posbindu PTM dan meningkatkan pemahaman warga tentang pentingnya kegiatan Posbindu PTM.

\section{Pengendalian hipetensi}

Tabel 2. Distribusi peserta berdasarkan jenis kelamin dan umur $(\mathrm{n}=83)$

\begin{tabular}{lcc}
\hline \multicolumn{1}{c}{ Variabel } & Jumlah & $\%$ \\
\hline Jenis kelamin & & \\
$\quad$ Laki-laki & 21 & 25,3 \\
Perempuan & 74,7 & 74,7 \\
& & \\
Umur & 4 & \\
Old (75 -90 tahun) & 18 & 21.62 \\
Elderly (60 -74 tahun) & 48 & 57.83 \\
Middle age (45 -59 tahun) & 13 & 15.66 \\
Adult $(<45$ tahun) &
\end{tabular}

Berdasarkan tabel 2. dapat dilihat bahwa sebagian besar $(74,7 \%)$ peserta berjenis kelamin perempuan dan lebih dari setengah $(57,83 \%)$ peserta berusia middle age ( $45-59$ tahun) dengan rentang usia 29 - 85 tahun.

Hal ini didukung oleh penelitian yang dilakukan oleh Sari \& Savitri, (2018) yang mendapatkan perempuan lebih bersikap positif dibandingkan laki-laki dalam mengontrol kesehatan. Mayoritas laki-laki di RW 05 bekerja sehingga menjadi hambatan untuk rutin setiap bulan datang ke Posbindu. Menurut Fuadah \& Rahayu, (2018) faktor usia juga mempengaruhi pemanfaatan Posbindu. Warga yang berusia 40-50 tahun akan lebih memikirkan kesehatan agar aktivitas mereka tidak terganggu dan tidak menghambat dalam mencari nafkah sehingga mereka lebih memanfaatkan pelayanan kesehatan. Sedangkan warga yang berusia lanjut atau di atas 60 tahun kebanyakan melakukan pemeriksaan setelah sakit dan memerlukan jenis pelayanan kesehatan yang lebih luas. Temuan ini berbeda dengan penelitian yang dilakukan oleh Sari \& Savitri, (2018) yang menyatakan bahwa berapapun usia warga tidak berhubungan dengan keaktifasn pemanfaatan Posbindu PTM yang berarti semua usia baik usia dewasa ( $<45$ tahun) maupun usia lansia (75-90 tahun) dapat memanfaatkan Posbindu. 
Tabel 3. Distribusi warga berdasarkan tekanan darah dan kadar kolesterol total $(n=83)$

\begin{tabular}{lcc}
\hline \multicolumn{1}{c}{ Variabel } & Jumlah & $(\%)$ \\
\hline Tekanan darah $(\mathrm{mmHg})$ & & \\
$\quad$ Normal & & \\
$\quad$ Sistolik $<120$ & 26 & 31,3 \\
$\quad$ Diastolik $<80$ & & \\
Prehipertensi & & \\
$\quad$ Sistolik 120-139 & 29 & 34,9 \\
$\quad$ Diastolik $80-89$ & & \\
Hipertensi & & \\
$\quad$ Sistolik $\geq 140$ & 28 & 33,7 \\
$\quad$ Diastolik $>90$ & & \\
Kadar kolesterol total (mg/dl) & & \\
$\quad$ Meningkat $\geq 200$ & 40 & 48,2 \\
$\quad$ Normal $<200$ & 43 & 51,8 \\
\hline
\end{tabular}

Tabel 3 diperoleh sebanyak 33,7\% warga menunjukkan tekanan darah hipertensi sedangkan hasil pemeriksaan kolesterol darah hampir berimbang antara nilai kadar kolesterol yang normal dan kolesterol yang tidak normal.

Temuan ini mungkin dikarenakan bagi warga yang menderita hipertensi dan sudah mengikuti Posbindu sudah diberikan pengobatan rutin. Beberapa warga sudah mengkonsumsi obat anti hipertensi secara rutin. Selain itu adanya petugas kesehatan dari puskesmas yang selalu hadir dalam kegiatan Posbindu memungkinkan warga dapat langsung berkonsultasi tentang keluhan yang dialaminya. Petugas kesehatan di Posbindu Soka Indah menempati meja 4 yaitu melakukan kegiatan identifikasi. Petugas kesehatan segera melakukan rujukan ke Puskesmas Jalan Kutai ketika menemukan hasil pengukuran yang tidak normal.

\section{Analisis hubungan pemanfaatan Posbindu dengan pengendalian hipertensi}

Berdasarkan pada perhitungan analisis statisrik didapatkan dari semua warga yang mengalami hipertensi sebanyak $17,9 \%$ warga yang aktif memanfaatkan posbindu sedangkan dari semua warga yang tekanan darahnya prehipertensi hanya $41,4 \%$ yang tidak aktif memanfaatkan posbindu.
Tabel 4. Hubungan pemanfaatan posbindu dengan tekanan darah dan kadar kolesterol total berdasarkan analisis uji Chi-square $(n=83)$

\begin{tabular}{lccccc}
\hline \multirow{2}{*}{ Variabel } & \multicolumn{5}{c}{ Pemanfaatan posbindu } \\
& \multicolumn{2}{c}{ Tidak aktif } & \multicolumn{2}{c}{ Aktif } & Nilai p \\
& $\mathrm{n}$ & $\%$ & $\mathrm{n}$ & $\%$ & \\
\hline Tekanan darah & & & & & \\
$\quad$ Hipertensi & 23 & 82,1 & 5 & 17,9 & 0,005 \\
$\quad$ Pre hipertensi & 12 & 41,4 & 17 & 58,5 & \\
$\quad$ Normal & 18 & 69,2 & 8 & 30,8 & \\
& & & & & \\
Kadar kolesterol & & & & & \\
total & & & & & 0,508 \\
$\quad$ Meningkat & 26 & 65 & 14 & 35 & \\
$\quad$ Normal & 27 & 62,8 & 16 & 37,2 & \\
\hline
\end{tabular}

Analisis Chi-square dengan tingkat kesalahan 0,05 diperoleh nilai $\mathrm{p}=0,005$ artinya secara statistik terdapat hubungan yang bermakna antara tekanan darah dengan pemanfaatan posbindu. Dari semua warga dengan kadar kolesterol total meningkat sebanyak $35 \%$ yang aktif memanfaatkan posbindu sedangkan dari semua warga yang kadar kolesterol normal sebanyak $37,2 \%$ yang aktif memanfaatkan posbindu. Uji chi-square didapatkan nilai $\mathrm{p}=0,508$ yang berarti tidak ada hubungan kadar kolesterol total dengan pemanfaatan posbindu (tabel 4)

Temuan menunjukkan ada hubungan tekanan darah dengan pemanfaatan Posbindu. Hal ini sesuai dengan penelitian yang dilakukan oleh Sari \& Savitri, (2018) yang menemukan bahwa ada hubungan yang signifikan antara kebutuhan dengan pemanfaatan posbindu PTM. Warga yang sudah benar-benar mengeluh sakit dan mencari pengobatan lebih aktif memanfaatkan Posbndu dibandingkan dengan warga yang merasa tidak membutuhkan. Sebagian besar warga RW 05 memanfaatkan Posbindu kemngkinan karena ingin mengetahui penyakit hipertensi atau penyakit tidak menular secara dini, memperoleh informasi kesehatannya dan pelayanan Posbindu mudah diakses karena hanya berjarak kurang dari satu kilometer dari rumah. Warga yang merasa tidak aktif karena merasa sehat dan dapat memeriksakan kesehatan di Puskesmas atau rumah sakit tempat mereka bekerja. 
Hasil temuan diperoleh tidak ada hubungan kadar kolesterol total dengan pemanfaatan posbindu. Hal ini kemungkinan disebabkan kegiatan pemeriksaan kolesterol total tidak secara rutin dilakukan di Posbindu Soka Indah sehingga warga tidak mengetahui apakah mereka mengalami hiperkolesterolemia. Selain itu ketersediaan sarana kesehatan juga dapat mempengaruhi. Fasilitas Posbindu sudah cukup memadai baik gedung maupun alat kesehatannya. Namun perlu menambahkan alat ksehatan seperti alat mencek gula darah dan kolesterol karena selama ini Posbindu masih menggunakan gedung Posyandu dan memakai alat kesehatan Posyandu Balita. Ketua kader kesehatan telah mengajukan proposal kepada pihak Kelurahan agar didirikan Gedung Posbindu

Pemanfaaatan pelayanan kesehatan termasuk Posbindu adalah hasil proses pencaraian pelayanan kesehatan oleh seseorang maupun kelompok dan dipengaruhi oleh berbagai faktor (Fuadah, D. Z., \& Rahayu, N. F., 2018). Faktorfaktor yang mempengaruhi pemanfaatan Posbindu di RW 05 Kelurahan Bencongan Indah masih perlu dikaji lebih lanjut. Kegiatan pengabdian masyarakat selanjutnya perlu menganalisa faktor-faktor yang berhubungan dengan pemanfaatan Posbindu PTM dan meningkatkan pemahaman warga tentang pentingnya kegiatan Posbindu PTM.

\section{KESIMPULAN}

Kegiatan pengabdian kepada masyarakat pada warga RW 05 Kelurahan Bencongan Indah Tangerang Banten dapat disimpulkan sebagai berikut:

1. Pemanfaatan posbindu PTM Soka Indah dalam kurun waktu April - Mei 2019 oleh warga termasuk kategori rendah $(36,1 \%)$

2. Sebagian besar $(74,7 \%)$ peserta berjenis kelamin perempuan dan lebih dari setengah $(57,83 \%)$ peserta berusia middle age (45-59 tahun) dengan rentang usia 29-85 tahun.

3. Sebanyak $33,7 \%$ warga menunjukkan tekanan darah hipertensi sedangkan hasil pemeriksaan kolesterol darah hampir berimbang antara nilai kadar kolesterol yang normal dan kolesterol yang tidak normal.

4. Terdapat hubungan yang bermakna antara tekanan darah dengan pemanfaatan Posbindu dan tidak ada hubungan kadar kolesterol total dengan pemanfaatan Posbindu

Dari pemaparan mengenai pemanfaatan Posbindu PTM terhadap pengendalian hipertensi maka saran yang dapat disampaikan oleh tim adalah:

1. Pihak Puskesmas tetap melaksanakan Posbindu PTM dan program penyuluhan pada warga RW 05 khususnya pasien hipertensi dan perawatannya secara rutin sehingga dapat meningkatkan pengetahuan pasien hipertensi dan melakukan perawatan mandiri.

2. Warga yang menderita hipertensi dan keluarga diharapkan lebih aktif memanfaatkan Posbindu Soka Indah. Dukungan keluarga berupa diingatkan jadwal Posbindu, diantar ke Posbindu dan ditemani ke Posbindu sangat diperlukan agar tekanan darah dapat terkontrol dan dikendalikan.

3. Sosialisasi mengenai Posbindu Soka Indah perlu ditingkatkan lagi agar warga mempunyai pengetahuan yang merata tentang manfaat kegiatan Posbindu untuk mengetahui faktor resiko penyakit tidak menular secara dini dan pencegahan komplikasi penyakit tidak menular.

4. Melakukan pendataan di warga RW 05 untuk meningkatkan sosialisasi tentang sasaran Posbindu PTM adalah kelompok masyarakat sehat, berisiko dan penyandang penyakit tidak menular yang berusia 15 tahun ke atas.

5. Fasilitas peralatan perlu ditambahkan seperti alat cek laboratorium. Pengurus Posbindu dapat memanfaatkan sumber-sumber pembiayaan yang potensial seperti membentuk kemitraan melalui CSR (Corporate Social Responsibility), membuat arisan warga dan sumbangan dari tokoh masyarakat.

6. Petugas kesehatan bekerja sama dengan kader membuat jadwal kegiatan Posbindu Soka Indah yang disesuaikan dengan kondisi warga dan menyelenggarakan kegiatan-kegiatan yang menarik di Posbindu Soka Indah seperti senam sehat bersama, program gizi atau makanan sehat dan lain-lain. 
7. Bekerja sama dengan Petugas Promosi Kesehatan atau Karang Taruna untuk membuat media promosi kesehatan berupa leaflet, poster dan brosur maupun media elektronik.

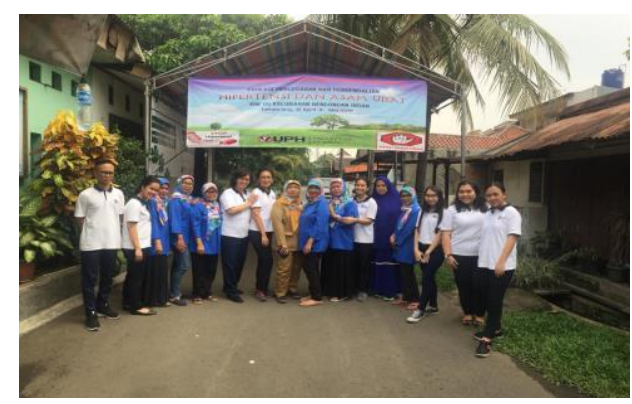

Foto bersama Kader kesehatan RW 05 dengan tim PkM UPH

\section{UCAPAN TERIMAKASIH}

Ucapan terimakasih disampaikan kepada Kepala UPT Puskesmas Kutai, Ketua RW 05, kader kesehatan Posbindu Soka Indah dan warga Kelurahan Bencongan Indah Kecamatan Kepala Dua Tangerang Banten yang telah memberikan kontribusi dalam pelaksanaan kegiatan ini.

Ucapan terima kasih juga disampaikan kepada Universitas Pelita Harapan yang telah mendanai kegiatan pengabdian masyarakat ini dengan nomor kegiatan PM-004/FoN/I/2018 tahun 2018

\section{REFERENSI}

Kementerian Kesehatan RI (2018). Hipertensi membunuh diam-diam, ketahui tekanan darah anda. Diakses dari http://www.depkes.go.id/article/view/180516 00004/hipertensi-membunuh-diam-diamketahui-tekanan-darah-anda.html
Kementerian Kesehatan RI (2019). Laporan Nasional Riskesdas 2018. http://labmandat.litbang.depkes.go.id/images/d ownload/laporan/RKD/2018/Laporan_Nasiona 1_RKD2018_FINAL.pdf

Fuadah, D. Z., \& Rahayu, N. F. (2018). PEMANFAATAN POS PEMBINAAN TERPADU ( POSBINDU ) PENYAKIT TIDAK MENULAR ( PTM ) PADA PENDERITA HIPERTENSI ( Utilization Of Integrated Posted Cooperation ( Posbindu ) of Non-Communicable Disease of Patients with Hypertension ). Jurnal Ners Dan Kebidanan, $5(1)$, 20-28. https://doi.org/10.26699/jnk.v5i1.ART.p020

Pusat Data dan Informasi Kemenkes RI. (2012). Penyakit TIdak Menular. Buletin Jendela Data Dan Informasi Kesehatan, 2, 1-14. https://doi.org/ISSN 2088-270X

Sari, D. W. R., \& Savitri, M. (2018). Faktor-Faktor yang berhubungan dengan Pemanfaatan POSBINDU Penyakit Tidak Menular (PTM) di Wilayah Kerja PUSKESMAS Kecamatan Setia Budi Kota Jakarta Selatan Tahun 2018. Jurnal Kebijakan Kesehatan Indonesia : JKKI, $7(2)$, $49-56$. https://doi.org/10.22146/JKKI.36849

Sihombing, R. M., Sitorus, F., Ompusunggu, F., Sidabutar, T., \& Bernadette, L. M. G. (2018). Edukasi pengendalian hipertensi dan asam urat pada warga kelurahan bencongan indah tangerang banten. https://prosidingpkmcsr.org/index.php/pkmcsr/article/view/167 $\underline{102}$ 